\title{
Analyzing the Impact of BTS on Resolving the Problem of Youth Mental Health
}

\author{
${ }^{1}$ Lambok Hermanto, ${ }^{2}$ Margareth Salindeho \\ ${ }^{1}$ Universitas President \\ ${ }^{2}$ International Relations Universitas President \\ Email Korespondensi:Lambok@president.ac.id, margarethdsalindeho@gmail.com
}

\begin{abstract}
This Journal outlines the efforts of BTS as a K-pop boy group to help to resolve the problem of Youth Mental Health, in which Korea itself has a background as one of the countries with the most mental health cases in the world. More deeply, in this study, the writer conducted an analysis of several forms of BTS activities that show their efforts in reducing mental health problems, in this case including; song lyrics in the BTS album, the social campaign they run with UNICEF, "Love Myself", and finally the public response to these BTS efforts. And in the results of this research, it can be seen that BTS does indeed have a positive impact through their songs lyrics and social campaigns. This can be seen from the response of the public who claimed to feel "healed", found motivation, and also forgot their problem after listening to BTS songs. In addition, in social media, it can also be seen how with the \#BTSLoveMyself campaign, the users of this hashtag also provide support to fellow people with mental health problems.
\end{abstract}

Keywords: Boy Band, BTS, K-Pop, Mental Health, Youth,

\section{INTRODUCTION}

Developing since the early 2000s, South Korea is considered to have successfully developed and promoted its culture on a large scale. Known as the Korean Wave, South Korea provides a real picture of all aspects of the country through the entertainment industry, especially TV drama and pop music that has its own Korean characteristics.

Specifically speaking of pop music, South Korea itself is known for its genre of "K-pop" which is a combination of various types of music genres that are delivered with a Korean style. The hallmark of K-pop music itself cannot be separated from the boy-group and girl-group systems that carry the music. In the system, boy-groups and girl-groups who will debut as K-Pop artists will generally be required to go through a period of training for singing, dancing and rap in order to have high selling power in the entertainment industry market. With various abilities and attractions possessed by K-Pop artists, this then makes the K-Pop genre flourish very quickly and large. With dances and songs performed by these K-pop groups, a lot of fan base was formed which was not only limited to South Korea but also Asia and the rest of the world. With the development of this Kpop sector, various layers of the international community also got an impact, such as by looking at examples of how to dress like the $\mathrm{K}$-pop artists that became a style that is imitated by many international communities, not to mention also the type of food, the use of Korean language, even songs and the dances of the artists are imitated by many people. Here, K-Pop already gives a good impact on South Korea itself to promote this country.

In addition, the rising popularity of $\mathrm{k}$ pop artists indirectly impacts young people in Korea to have dreams and desire to join the kpop entertainment industry. In this case, KPop has had an impact on many people, even Korea itself as its home country. Furthermore, one of the K-Pop artists who have a big impact is BTS.

BTS is a 7 membered boyband that is currently at the peak of their career since they're titled as biggest group in the world due to various international achievements and recognition that they have achieved, such as the award of the best artist, best album, best song and best group since 2017 in Korea, and has topped the billboard charts since 2017, earning the nickname of the best group and top artist in America since 2018 (BBC, 2018). However, debuting in 2013 under the auspices of the Big Hit Entertainment agency, BTS began their career as a group that did not have so many opportunities to appear on music shows due to the group's background as an 
artist who came out of a small agency namely Big Hit Entertainment, which is this agency not included in the ranks of large agencies such as SM Entertainment, YG Entertainment and JYP Entertainment.

Even so, BTS with its unique trademark as a K-pop idol rooted in the HipHop music genre is in fact judged to be more free and able to express their opinions bluntly through music works and their actions, compared to other k-pop idols who is more relying on their big agency for their music production and activities, in which for K-pop idols in general, due to a strict contract system, artists only need to practice singing, dancing, and rap, while for the production of music and style will be arranged by a special team provided by the agency. Therefore, Korean idol artists often get the music stigma of class "B" which means less qualified in musical ability and creativity because basically they do not have many opportunities to channel their creativity in the music they bring themselves, but work like a "robot" that controlled by the agency (Valge \& Hinsberg, 2019).

On the other hand, BTS which was born from a small agency that since its inception has been known as one of the idol groups that has high quality music. With roots in the genre of Hip-hop music which is a type of music with loud lyrics and criticism, each BTS member actively plays a role in every music production including writing lyrics as a channel for their creativity. Thus, with this Hip-Hop genre kind of idol, BTS developed into an artist who is not only as reliable in singing, dancing or rap as other K-pop idols, but also they give their own opinions and criticisms scathing about social, political, cultural issues to mental health that occurs in society through their music and action. In addition, aside from music with the theme of love between couples, BTS comes with a variety of other different love themes such as self-love, brotherhood, and not forgetting the theme of "dreams" aimed for the millennial generation (Wiradarmo, 2019). Here, that is one of the reasons for the booming popularity of BTS globally.
In the songs that have been released, it can be seen how BTS as a public figure always tries to talk about various topics inherent in society, as a few examples, the songs "Whalen 52" and "Jamais Vu" released by BTS talk about issues related to youth empowerment which at times often feel alienated and want to give up, the song "21st Century Girl" talks about protecting women, the song "Silver Spoon" speaks about stereotypes and burdens received by millennial, the song "Spine Breaker" and "Go Go" criticize the culture of consumerism of millennial, the song "The Last" talks about the depression experienced by them, besides that there is also the song "Spring Day" which is interpreted as a form of work to commemorate the victims of the Ferry Sewol ship accident which was considered a form of failure in the political game to the point of it has been tried to be covered up by the media and the government (Wiradarmo, 2019). With this background of the success of BTS, the group has been considered to become an icon that is often followed, emulated and influenced the community positively.

On the other side, speaking about Youth Mental Health, South Korea is one of the countries with the highest mental illness cases in the world. It is noted that 1 out of 4 people in Korea living through this problem, thus the suicide rate is always increasing every year (The Straits Time, 2017). Following this fact, BTS through their song, interviews, and social media has often issued statements to support everyone (more specifically teenagers) who are dealing with this problem and encouraging them not to give up or even take actions that are harmful to themselves. In the form of musical works, several BTS songs have frankly discussed this issue, namely "Love Yourself", "Idol", "The Last", "No More Dream", "N.O", "Sea" and "The Last" (Wiradarmo, 2019). With a career background that was built with difficulty, BTS tried to convince young generation with these songs, that they are not alone and that the hard times would surely pass, and beautiful things will happen. In line with that, based on personal experience, BTS also often 
tells how they are also often in a bad situation, but rather than giving up, getting up and surviving is the best thing for young people.

Moreover, another form of BTS efforts to raise mental health awareness is by joining UNICEF in the "Love Yourself" campaign that aims to help children and teens against the violence and getting through mental illness with the hope of making the world a better place through the music (UNICEF, 2017). On this campaign, there are several forms of implementation, namely the first, using \#BTSLoveMyself in social media to push young people out of problems of selfharm, depression and suicidal intention. Furthermore, BTS also raised funds to help people in the rehabilitation period for mental health prevention, and also BTS released an album with the exact theme, Love Yourself.

From here, the object of this research will be focusing on the teenagers who have problems with mental health, more specifically those who are familiar with BTS and their works. Utilizing statements or reviews conducted by them on several music sites, blogs and official websites of the UNICEF campaign, this article will look at how BTS has an impact on young people in dealing with mental health problems

\section{Research Question}

How BTS gives a positive imp act on solving the problem of the mental health of young people?

\section{THEORITICAL FRAMEWORK}

BTS as a public figure has made several efforts to help young people get out of mental illness problems. By utilizing its influence, there are 2 ways BTS does is through music that "heals" and runs a campaign titled "Love Myself" and uses \#BTSLoveMyself.

In this research, I will use several theories to explain how these two BTS efforts have an impact on every young person with mental problems. First, to understand the BTS' way as an effort to reach people with mental health, I will use the Popular Culture theory from John Storey (2015) in "Cultural
Theory and Popular Culture". Here, in the meaning of Pop Culture, taking the understanding conveyed by Raymond William in this book, Popular culture has 4 meanings, namely 'something that well-liked by many people'; 'inferior kinds of work'; 'work deliberately setting out to win favour with the people'; and 'culture that actually made by the people for themselves'. Here, Pop culture can simply be interpreted as a "culture that is widely favoured or well-liked by many people" (Storey, 2015).

In achieving the objectives of Pop Culture, the Utilization of Television, Newspapers, Radio, Movies, Songs and social media then included as the hallmark of implementing pop culture in society as general or broadly. In this case, the use of media that can be easily accessed by the community is considered as an efficient practical form in conveying everything that is intended by someone to be digested, enjoyed, and liked by the public at large. (Tanudjaja, 2007).

Furthermore, when the goal of Pop Culture is achieved, which is where a work can be liked by many people, then many impacts can be received by the people included in it. In this case, when a group of people in large numbers can reach the stage of liking a work in large quantities, it is likely that these people can follow or take examples of actions that are emitted and intended in the work or even the person behind the work.

With this basis, then I will try to see, how the BTS efforts as outlined in their work containers can win the hearts of many people, more specifically those with mental health problems and influence them.

In the second part, responding to the procurement of the campaign titled "Love Myself" and the use of \#BTSLoveMyself, I will use the theory of Public Communication Campaign discussed by Charles K. Atkin and Ronald E. Rice in a journal entitled "Theory and Principles of Public Communication Campaign".

Here, they defined Public communication campaigns as "a purposive attempt to inform or influence behaviors in 
large audiences within a specified time period using an organized set of communication activities and featuring an array of mediated messages in multiple channels generally to produce noncommercial benefits to individuals and society" (Atkin \& Rice, 2009).

In procuring campaigns that have an impact on many people, Atkin and Rice argues that the application of social marketing can emphasize an audience-centered consumer orientation by seeking promotion in an attractive and optimal way to achieve influential campaign objectives. Moreover, the application of social marketing is applicable in order to promote a desirable behavior as the theme of the campaign.

Campaign generally contains two elements of messages, namely Awareness message to provide information about an issue or problematic situation at the time and Instruction massage aimed at providing information about what should be done in the problematic situation. Here, social marketing is needed so that the message can arrive and be properly digested by the public. For this reason, several social marketing strategies that can be used are through social media. In connection with the development of technology and communication, the use of social media is believed to be able to make a major contribution as a communication platform and to find out the latest information. Therefore, the use of social media can be used as a social marketing strategy in implementing campaigns.

Furthermore, in general discussing the impact of BTS, I will also discuss the system of public figures' reputation discussed by Xiaoxuan Ciu in Atlantis Press. In his writings stated that Public Figure is "the person who have a certain social status or social awareness within a certain range, impactful, and can benefit from the community, and closely related to social interests, the occasional cause of the exception." (Cui, 2017). In here, it is understood that with the social status and popularity possessed by a public figure, then that person can easily show or give an example of an action that results in the action being followed by the public who see it.

At the end, I using the theories above to explain the impact of BTS as a public figure, through music and campaigns to reduce the number of young people with mental health problems.

\section{RESEARCH METHODOLOGY}

This research will be focusing on analyzing some of efforts carried out by BTS to solve a problem regarding a large number of mental illness sufferers among adolescents. In this case, by focusing on the use of works by BTS as musicians, as well with the social campaign actions carried out by them, the writer will then collect data and information through BTS song lyrics and the "Love Myself" social campaign with UNICEF as the two main elements to be analyzed.

In the first element, the writer will analyze deeper about the lyrics in songs produced by BTS. Here, the writer will take a sample of 3 songs from all the work that has been done by BTS. The lyrics in question are all the lyrics that provide a "healing" effect or contain words of support to encourage people who go through difficult times related to mental health. From these lyrics, the writer will then collect comments from people who are dealing with mental illness that listening to BTS' songs. In this case, the author will take 3 samples of comments for each song which is contained on the official You-tube channel of BTS itself. Here, the writer decides to take a sample based on BTS You-tube channel because the writer believes that they are the people who have listened to BTS music, so they are the ones who deserve to give comments on whether the BTS songs affect their mental state or not.

Furthermore, related to the second element, the writer will analyze more deeply about the implementation of the social campaign titled "Love Myself" issued by BTS, in collaboration with UNICEF since 2017. Here, by focusing on two main activities in this campaign, namely the use of \#BTSLoveMyself and voluntary fundraising, the author will take examples of BTS 
solicitation actions through their social media Twitter activities, and also collect data on the development of fundraising from the initial release of the campaign to this time.

In the end, after all the data has been collected, the author will provide an interpretation of how all the efforts that have been made by BTS have an impact on young people's problems with mental health.

\section{ANALYSIS}

As a group that is active in entertainment industry, BTS has released variety of works that are considered interesting and liked by many people, both inside and outside Korea, as K-Pop culture has also spread around the world. By becoming part of Korean pop culture that is famous around the world, BTS through its work since debut has voiced their concern for various social issues, especially about mental health, in which through songs produced by BTS members themselves. In addition, some BTS activities are also attached to social events with a mental health theme, such as collaboration with UNICEF.

By raising the theme related to mental health through their activities and songs, BTS then considered to have succeeded in creating positive content with which could make everyone who heard it become aware of mental health problems, and also those who were experiencing it could feel encouraged. This can be seen from how many of their songs have become popular and liked by many people. Thus, in accordance with the objectives in Pop Culture discussed in the previous theoretical framework, it can be seen how BTS utilizes the use of their songs that are spread easily through the internet, radio and world music platforms, as well as an educative work that is well-liked by many people. Here, that's how BTS can become a public figure with a large impact on the public, especially those with mental health problems

\section{Songs with the theme of "Love Yourself"}

First, to see this in depth, several songs can be observed in order to understand the BTS message directly to young people with health problems.

\section{a. Love Myself: Answer}

This song was written by three BTS members; RM, J-hope and Suga, are one of the songs included on the BTS album released in 2017, titled LOVE YOURSELF 結 結 ANSWER, which overall intends to tell a message that "Loving oneself is where true love begins" (Big Hit Entertainment). In this song that talk about the story of a journey to self-love, BTS in it calls for the importance of loving oneself for everyone. This is shown in some of the lyrics below:

"Loving myself might be harder than loving someone else, Let's admit it.

The standards I made are more strict for myself.

The thick tree rings in your life, It's part of you, it's you.

Now let's forgive ourselves

Our lives are long, trust yourself when in a maze

When winter passes, spring always comes

You've shown me I have reasons

I should love myself (oh)

The me of yesterday, the me of today, the me of tomorrow

(I'm learning how to love myself)

With no exceptions, it's all me

Maybe there's no answer

Maybe this isn't the answer either

It's just that loving myself

Doesn't require anyone else's permission

I'm looking for myself again

But I don't wanna die anymore

Me, who used to be sad

Me, who used to be hurt

It'll make me more beautiful

Yes, I have that beauty

Knowing that is going

On the path to loving myself

It's what I need the most

I'm walking for myself

It's an action needed for me 
My attitude towards myself

That's the happiness I need for me

I'll show you what I got

I'm not afraid because it's me

Love myself"

With such lyrics on their song, BTS spreads a deep message about self-love to every listener. Through the comments column of this song that was uploaded on the official BTS' Youtube channel, some listeners then left comments on how this song meant for their mental health.
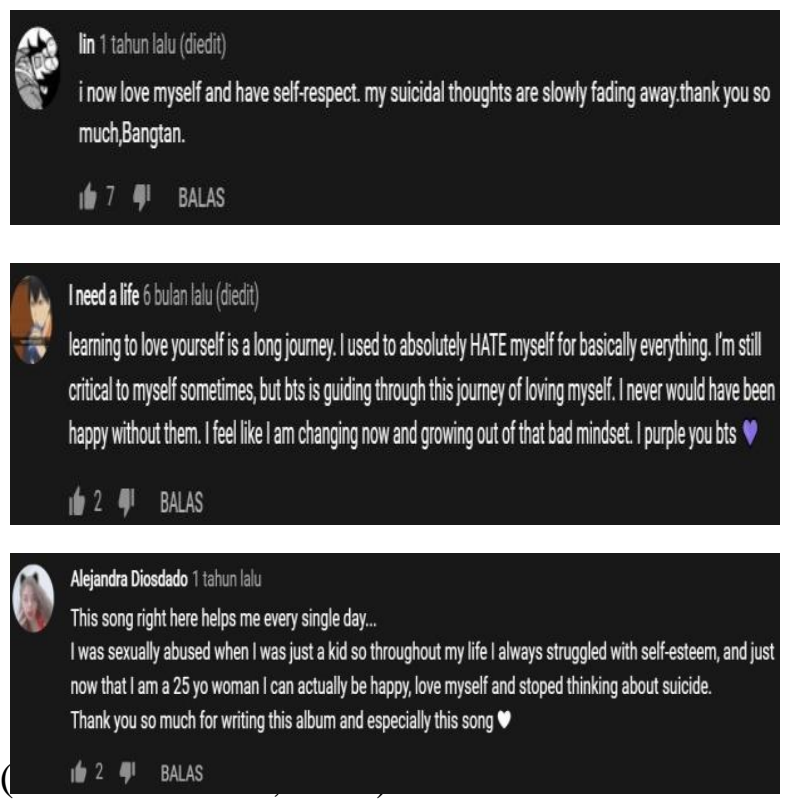

In this song's comments column, listeners give their testimonials about how this song which is written by BTS members has an impact on how they think about their selves. It is also understood how everyone that has a bad experience related to the way they think and treat themselves, in the end, they can change towards a more positive direction through this song.

\section{b. Outro: Epiphany}

Similar to Love Myself, this song sung by Jin BTS is also one of the songs from the BTS album, LOVE YOURSELF 結 ANSWER. In this song, it is emphasized that every human being might not be perfect, but every people basically has his or her own beauty. It doesn't matter how lacking we are, but we are all precious. For that, first thing that should be loved before anyone else is you. In the song, the lyrics say this:

\section{"I may be a bit blunt, I may lack some things}

I may not have that shy glow around me

But this is me

My arms, my legs, my heart, my soul

\section{I'm the one I should love in this world Shining me, the precious soul of mine I finally realized, so I love me Not so perfect but so beautiful I'm the one I should love"}

With the lyrics in this song, it can be seen that BTS is also foaming to make its listeners aware of the uniqueness that everyone has. By not constantly pursuing perfection, but because we are valuable, we shouldn't hate ourselves, but rather to love ourselves. Here, the message referred to BTS was successfully reached his listeners. This can be seen through the comments column where the song is uploaded on the official BTS' Youtube channel, as follows:

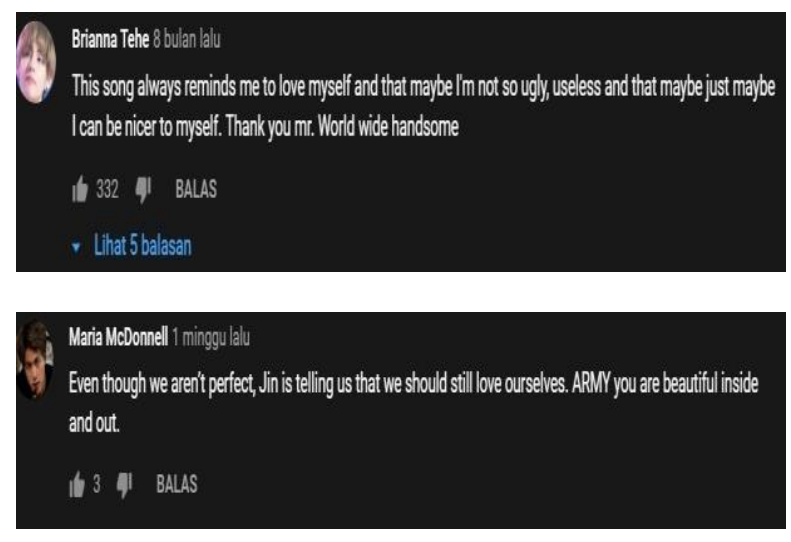

(Big Hit Labels, 2018)

From these comments, it can be seen that the BTS message in this song can be successfully received by the listeners. And not only that, listeners who feel they have understood the message even trying to convey the purpose of this song in words that are easier for others to understand, in which to 
love themselves is a very important thing to do.

\section{c. $2 ! 3$ !}

Unlike the previous songs, this song is included in another BTS album, titled "You Never Walk Alone" which was released in 2015. The album itself generally has a message of comfort and hope to the youth of this generation, that it is stated "We can laugh if we are together" (Big Hit Entertainment, n.d.). More specifically, 2 ! 3 ! is one of BTS songs that was aimed to their loyal listeners or their fans. In this song, BTS provides support and encouragement to every listener. Moreover, BTS expressed their presence and desire to continue to help listeners out of their problems, in where days feel hard or when their mental state is bad, through their music, BTS can help them to get it through. The core lyrics that describe the message in this song, say that:

$$
\begin{gathered}
\text { It's okay! } \\
\text { Come on, when I say "one, two, } \\
\text { three", forget it! } \\
\text { Erase all sad memories, } \\
\text { And smile, holding onto each other's } \\
\text { hands. } \\
\ldots \\
\text { Hoping for more good days in the } \\
\text { future } \\
\text { I just wanted to make you smile } \\
\text { I wanted to do good. }
\end{gathered}
$$

In line with the album's title where the song is incorporated, BTS conveys a message that every difficult day can be forgotten slowly. With the lyrics above, it is hoped that listeners can look forward to a better future than focusing too much on sad memories that existed before. This message can also be well received by BTS fans, seen in the comments column of this song which uploaded by the official BTS channel.

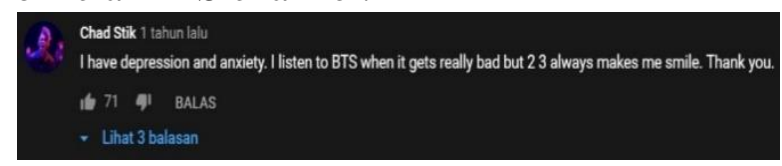

Alexandra 4 bulan lalu

this song never fails to calm me down, make me happy and give me hope!

(BANGTAN TV, 2018)
In the comments above, it can see how fans responded to this song. With their recognition of how calm they are after looking up for this song. It can be understood that BTS has achieved their goal of providing comfort and hope for the listeners.

In the end, as the spread of pop culture developed throughout the world, BTS, in this case, has succeeded in spreading a deep social message to listeners to its music throughout the world. With music and the use of social media, BTS can win the hearts of many people through educative and constructive works, which in the theme of mental health, BTS is trying to make a good impact on everyone, especially young people who are currently in a high case of mental illness.

\section{Social Campaign of "Love Myself"}

As another BTS effort to address the mental health issues experienced by young people, there are also social campaigns undertaken in collaboration with UNICEF. With the title "Love Myself", BTS started a series of social campaigns in early 2017. In this project, BTS together with UNICEF focused on handling various cases of violence that occurred to young people, including selfviolence caused by mental illness or violence against others, like bullying (Big Hit Entertainment, n.d.).

In its implementation, this campaign is promoted globally throughout the world with its headquarters in Korea. Just as the Public Communication Campaign theory discussed in the previous theoretical framework, the Love Myself Campaign has utilized social marketing tactics to deliver awareness messages to provide information about the issue of mental health and also the instruction message about what to do in order to face the issue. Here, BTS uses several platforms to spread the message of this campaign, such as using \#BTSLoveMyself on social media Twitter, opening the Love Myself booth around the BTS concert area and also raising funds globally to help run the campaign to schools and also as a grant to mental illness patients. With the use of various platforms, it can be seen how BTS strives to be able to 
influence many people, both directly and indirectly.

Last updated on 30 November 2019, there were at least 2.6 billion of South Korean Won or equal to 2.1 million dollar accumulated funds collected from this campaign. These funds were collected from a number of events organized by BTS and UNICEF itself, such as: 1) KRW 500 million from Big Hit Entertainment and the seven BTS members; 2) Donations of $3 \%$ of the income from the sales of physical albums of the Love Yourself series, 3) Donations of $100 \%$ of the income from the sales of official goods for the LOVE MYSELF campaign , 4) Donations installed by UNICEF, as well as contributions from media partners such as 5) LINE Donation Sticker, 6) Giveticon Cocoa, 7) Together with Cocoa, and 8) Happybean (Big Hit Entertainment, n.d.).

Moreover, as for the use of \#BTSLoveMyself on Twitter, there were $11,811,497$ tweets that occurred. In this campaign activity on social media, it can be seen how BTS and UNICEF share various kinds of messages and promotions which are shown in the form of videos, posters and photos, as follows:

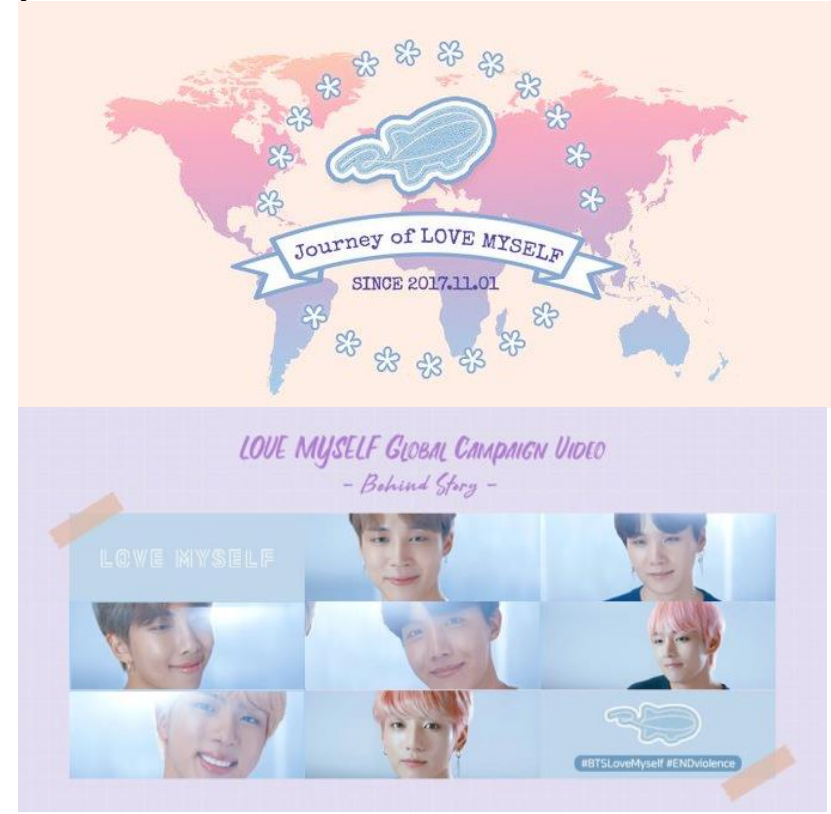

Responding to the implementation of this campaign on Twitter, with the large number of \#BTSLoveMyself activities demonstrating how high the public's enthusiasm is in responding to it. In various forms of tweets on
Twitter, it can be seen how the message of this campaign also ultimately succeeded in influencing the way people think and act towards themselves and others, that is more positively. As an example of the tweet below:
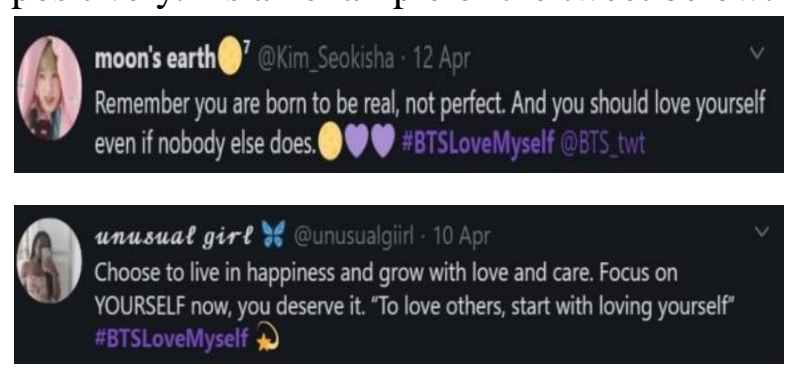

From this \#BTSLoveMyself activity, it can be understood that more and more people understand BTS's message to the wider community, which is to be able to do good to themselves, and also others, which is a form of us loving ourselves.

In the end, it can be seen how this campaign can run well and get success on the activities that have been carried out, which is the delivery of messages that received well by the public. BTS here has also succeeded in playing the role of a good public figure by providing a good example for the public. On another side, BTS's efforts in helping mental health problems may be well done, also public response may also have been achieved well. However, it should be understood that mental health will is actually the responsibility of everyone to keep it positive. Thus, it then becomes a hope that everyone can remember BTS' messages that they have received and always practice them on a daily basis. Because a mental problem is a challenge that will always be faced by everyone. And in the end, with good knowledge and support, everything will depend on yourself again to win over the problem.

\section{CONCLUSION}

Overall, the research on the impact of BTS's efforts on Youth Mental Health is limited to certain matters, such as only 3 sample songs from all 3 BTS albums that talk about mentality, as well as listeners' opinions taken from You-tube comments that cannot be monitored its development. Therefore, it 
can be said that this research has not been able to draw final conclusions on the valid impact of these BTS efforts on the lives of their listeners over a long period of time. In addition, this study also has not been able to include a psychological perspective on how songs or the efforts of musicians can temporarily or permanently affect a person's health, therefore, the author personally believes that this research can still be explored more in order to find out how these BTS efforts can become a "therapy" session for youth with mental health problems.

\section{REFERENCES}

Atkin, C. K., \& Rice, R. E. (2009). Theory and Principles of Public Communication Campaigns . 3-16.

BANGTAN TV. (2018). Youtube. Retrieved from 2 ! https://www.youtube.com/watch?v=E30 APZxHh4c

BANGTANTV. (2018). Answer: Love Myself.

BBC. (2018). BTS: Who are they and how did they become so successful?

Big Hit Entertainment. (n.d.). BTS Dischography. Repackage Album: Love Yourself 結 "Answer":

Big Hit Entertainment. (n.d.). BTS Discography. Special Album: You Never Walk Alone:

Big Hit Entertainment. (n.d.). Love Myself.

Big Hit Labels. (2018, August 9). BTS (방탄소년단) LOVE YOURSELF 結 Answer 'Epiphany' Comeback Trailer.

Cui, X. (2017). The System of Public Figures' Reputation On the Judicial Judgment. 3rd International Conference on Economics, Social Science, Arts, Education and Management Engineering, 975-977.

Storey, J. (2015). Cultural Theory and Popular Culture; An Introduction. University of Sunderland: Pearson Education.

Tanudjaja, B. B. (2007). PENGARUH MEDIA KOMUNIKASI MASSA TERHADAP POPULAR CULTURE DALAM KAJIAN BUDAYA/CULTURAL STUDIE. 96-105.

The Straits Time. (2017, April 12). 1 in 4 Koreans experience mental disorders, but only10\% seek professional help: Survey. The Straits Time.

UNICEF. (2017). Love Myself. LOVE MYSELF.
Valge, C., \& Hinsberg, M. (2019). The Capitalist Control of K-pop: The Idol as a Product.

Wiradarmo, A. A. (2019). BTS: Isu Psikologis dan Sosial dalam Budaya K-Pop. Pijar Psikologi. 